\title{
MITOS SOBRE LA DONACIÓN DE ÓRGANOS EN PERSONAL DE SALUD, POTENCIALES RECEPTORES Y FAMILIARES DE POTENCIALES DONANTES EN UN HOSPITAL PERUANO: ESTUDIO CUALITATIVO
}

\author{
Katherine Gómez-Rázuri'1,a, José Ballena-López ${ }^{1, a}$, Franco León-Jiménez ${ }^{1,2, b}$
}

\begin{abstract}
RESUMEN
Objetivos. Explorar los mitos sobre la donación de órganos en un hospital nacional de Lambayeque-Perú, en el año 2014. Materiales y métodos. Se realizó un estudio cualitativo-fenomenológico con veinticuatro entrevistas a profundidad no estructuradas a personal de salud, potenciales receptores y familiares de potenciales donantes. El muestreo fue intencional opinático finalizado por saturación teórica de cada estamento. Se utilizó una guía de entrevista evaluada por cinco expertos. Se realizó triangulación de datos. Resultados. Veintitrés entrevistados (95,8\%) mostraron actitud favorable hacia la donación de órganos. En el Documento Nacional de Identidad, trece $(54,2 \%)$ refieren "no" a la donación. Los mitos fueron: la edad o enfermedades contraindican la donación; el receptor de un órgano experimenta actitudes de su donador y vive en él; la muerte cerebral es inmovilidad del cuerpo y un estado reversible; las religiones no aceptan la donación de órganos, esta afecta la integridad física y la resurrección, y existen preferencias en la lista de espera de donantes así como el tráfico de órganos. Conclusiones. Los mitos explorados en el presente estudio muestran perspectivas religiosas, socioculturales, psicológicas y éticas. La aparente falta de conocimiento del diagnóstico de muerte cerebral es el punto de partida que marca el proceso de donación. La existencia de un coordinador hospitalario, el rol de los guías espirituales y la correcta información brindada por medios de comunicación serían piezas clave para derribar estos mitos.
\end{abstract}

Palabras clave: Folclore; Obtención de tejidos y órganos; Trasplante de órganos; Muerte encefálica; Tráfico de órganos; Análisis cualitativo (Fuente: DeCS BIREME).

\section{MYTHS ABOUT ORGAN DONATION ON HEALTH PERSONNEL, POTENTIAL RECIPIENTS AND RELATIVES OF POTENTIAL DONORS IN A PERUVIAN HOSPITAL: A QUALITATIVE STUDY}

\begin{abstract}
Objectives. To explore the myths regarding organ donation at a national hospital in Lambayeque, Peru during 2014. Materials and methods. A qualitative-phenomenological study was performed using 24 unstructured in-depht interview of health personnel, potential recipients and relatives of potential donors. Sampling was intentional opinion-based, completed by theoretical saturation in each group. An interview guide was used, which was assessed by five experts, and data triangulation was performed. Results. Twenty-three interviewees $(95,8 \%)$ reported a favorable attitude towards organ donation. On their National Identification Document, thirteen $(54,2 \%)$ had marked "no" for donation. The myths were: age or illness can preclude donation; that the recipient may experience the donor's behaviours and lives in it; brain death is undestood as the immobility of the body and a reversible state; religions do not accept organ donation because it affects physical integrity and resurrection; and that there are preferences on the organ donor waiting list and that organ trafficking taxes place. Conclusions. Myths explored in this study involved religious, socio-cultural, psychological and ethical misperceptions. The apparent lack of knowledge of the brain death diagnosis is the starting point of the donation process. Therefore, the presence of a hospital coordinator, the role of spiritual leaders and the correct information provided by media would be key parts to dispell these myths.
\end{abstract}

Key words: Folklore; Tissue and organ procurement; Organ transplantation; Brain death; Organ trafficking; Qualitative analysis (Source: MeSH NLM).

\footnotetext{
Escuela de Medicina. Universidad Católica Santo Toribio de Mogrovejo. Chiclayo, Perú.

Hospital Regional de Lambayeque. Chiclayo, Perú.

Médico cirujano , ${ }^{\mathrm{b}}$ médico internista
}

Esta investigación fue presentada en el "VII Curso-Jornada de Investigación en Salud - 2014" llevada a cabo en la Universidad Católica Santo Toribio de Mogrovejo - Lambayeque donde obtuvo el primer puesto como informe final. Además, forma parte de una tesis para optar al título de médico cirujano. Recibido: 11-02-15 Aprobado: 09-03-15

Citar como: Gómez-Rázuri K, Ballena-López J, León-Jiménez F. Mitos sobre la donación de órganos en personal de salud, potenciales receptores y familiares de potenciales donantes en un hospital Peruano: Estudio cualitativo. Rev Peru Med Exp Salud Publica. 2016;33(1):83-91. doi: 10.17843/rpmesp.2016.331.2011 


\section{INTRODUCCIÓN}

El conceder órganos procedentes de donantes vivos o cadavéricos tiene como fin favorecer las condiciones de vida y salud de otra persona. Es un acto gratuito y voluntario, conforme lo expresa la Ley General de Donación y Trasplante de Órganos y/o Tejidos Humanos (Ley 28189), que en nuestro país no goza de una difusión ideal. Según un informe internacional del año 2014, Perú tiene una de las tasas mundiales más bajas de donantes fallecidos, con apenas 3,2 personas por millón de población (pmp), América Latina con un promedio de 8,8 pmp y España con 33-35 donantes pmp ${ }^{(1,2,3)}$.

El trasplante es considerado un tratamiento definitivo de varias enfermedades que reducen o anulan la función de un órgano o tejido y ponen en riesgo la vida. Son ejemplos: cirrosis hepática, atresia de vías biliares, enfermedad pulmonar obstructiva crónica, fibrosis quística, leucemias, aplasia medular severa, enfermedad renal crónica (ERC) debida a diabetes mellitus o enfermedad glomerular, valvulopatías cardiacas severas, arritmias ventriculares sintomáticas recurrentes, entre otras ${ }^{(4,5,6)}$.

El proceso comienza con la identificación de un potencial donante; continúa con la procuración del buen estado de órganos y tejidos hasta su ablación; luego, el transporte en condiciones especiales y tiempo limitado y, finalmente, su implantación. La condición del donante debe cumplir especificaciones: diagnóstico y certificación de muerte encefálica (coma estructural irreversible, ausencia de reflejos del tronco encefálico, ausencia de respiración espontánea); estudios serológicos para validación del donante (perfil de hepatitis viral, TORCH, VIH, HTLV, treponema y tripanosoma), y pruebas específicas para validación de órganos (urea, creatinina, ecografía, perfil hepático, glicemia, etc.). Además, la tipificación del HLA (antígeno humano de histocompatibilidad) para estudio de compatibilidad donante-receptor ${ }^{(1)}$.

Una investigación cualitativa en Chile sobre las razones para ser o no donante encontró como impedimentos: dudas de la honorabilidad y ética médica, desconocimiento de muerte cerebral y una imagen negativa del personal de salud ${ }^{(7)}$. En la región macronorte del Perú el Servicio de Procuración de Órganos y Tejidos registró las opiniones negativas de los familiares de posibles donantes durante los años 2000 al 2010, entre ellas: la preocupación por desfiguración del familiar; el desconocimiento del destino de los órganos; problemas con el sistema sanitario; desconocimiento del concepto de muerte encefálica, y las creencias religiosas ${ }^{(8)}$.
En una universidad particular del departamento de Lambayeque en Perú, los temores sobre la donación de órganos fueron: miedo a la extracción de órganos antes de estar verdaderamente fallecido, vida después de la muerte, y miedo a ser mutilado ${ }^{(9)}$. Además, según estudios, la actitud no favorable del personal de salud de áreas procuradoras de donación y trasplante (unidad de cuidados intensivos, emergencia y especialidades donde se realizan los mismos) es un obstáculo para el incremento de donación de órganos ${ }^{(10)}$.

En el año 2014 solo el 13,1\% de los 20611906 peruanos mayores de 18 años expresaron en su Documento Nacional de Identidad (DNI) la voluntad de ser donantes (11). En los peruanos adscritos al seguro integral, una de las enfermedades que más afecta la calidad de vida es la ERC. Su prevalencia es $111,1 \mathrm{pmp}$ y su incidencia es de 44,2 pmp. Se estima que existen 9490 pacientes con ERC en estadio final y solo 1500 reciben tratamiento. Así, en el 2013 se realizaron 147 trasplantes renales a nivel nacional. De ellos, 11 fueron en el departamento de Lambayeque ${ }^{(8,12)}$. La principal limitación para el trasplante sería la insuficiente disponibilidad de órganos, lo que acrecienta el tiempo de espera de los potenciales receptores; es decir: "sin donantes no hay trasplantes", puesto que no se toma en cuenta que "la donación de órganos empieza y termina en la sociedad" (13-15).

De acuerdo con lo expresado, los factores culturales, éticos, hospitalarios y otros, intervendrían en la visión acerca de la donación de órganos ${ }^{(14,16)}$. En nuestro medio, la información es vaga e imprecisa por eso es necesario abordarla como un fenómeno social. El objetivo del presente estudio es explorar los mitos sobre el tema en tres estamentos: personal de salud, potenciales receptores y familiares de potenciales donantes.

\section{MATERIALES Y MÉTODOS}

\section{DISEÑO Y POBLACIÓN DE ESTUDIO}

Se realizó un estudio cualitativo exploratorio con enfoque fenomenológico en un hospital nacional de Lambayeque en el año 2014. Los sujetos y criterios de selección fueron: a) potenciales receptores: edad mayor a 18 años; no vinculados con las ciencias de la salud, ni con la donación de órganos como estudiantes o profesionales; y pacientes diagnosticados con ERC grado $V$ no incluidos en la lista de espera nacional para trasplante. b) Familiares de potenciales donantes: edad mayor a 18 años; no vinculados con las ciencias de la salud ni con la donación de órganos; estudiantes o profesionales directamente relacionados (padres, hermanos, hijos, cónyuges o convivientes); contactados como mínimo tres 
meses después del fallecimiento del potencial donante. c) personal de salud: personal médico y de enfermería de los servicios de Emergencia, Unidad de Cuidados Intensivos y Nefrología del mismo hospital.

\section{MUESTREO}

De tipo intencional opinático "en bola de nieve". Se contactó a los investigados en los servicios del Hospital Nacional Almanzor Aguinaga Asenjo; además, se revisaron los registros del Servicio de Procuración de Órganos en el caso de los familiares.

Se negaron a participar familiares de potenciales donantes que no habían aceptado la donación de órganos, tres de ellos debido a encontrarse en otros departamentos del Perú, tres se rehusaron a la entrevista sin expresar motivos, y cinco no pudieron ser localizados con los datos brindados por el Servicio de Procuración de Órganos.

\section{DEFINICIÓN DE TÉRMINOS BÁSICOS}

Un mito se define como el complejo de creencias nacidas de distintos individuos, pero propagadas por la sociedad al tratar de explicar un fenómeno, forman parte de la "trama conceptual de la mente" (17). Potencial donante es aquella persona con muerte encefálica (cese definitivo e irreversible de las funciones encefálicas) sin contraindicación médica ni legal para la donación de órganos. Potencial receptor, es aquel cuyo órgano ha perdido su función y puede mejorar o resolver su condición mediante un trasplante ${ }^{(1)}$

\section{PROCEDIMIENTO}

Se realizó el abordaje mediante entrevistas a profundidad no estructuradas. Los investigadores fueron capacitados para lo cual se realizó previamente ocho entrevistas no incluidas en el estudio, esto permitió elaborar una lista de temas. Cinco expertos aprobaron esta guía (Anexo 1): dos coordinadores del Servicio de Procuración de Órganos y Tejidos de la región macronorte, un médico nefrólogo con capacitación en la procuración, un médico epidemiólogo y una doctora especializada en investigación cualitativa.

Las entrevistas se realizaron en hora y lugar concretados con cada sujeto (casa propia u oficina). Previamente, se brindó una hoja informativa y se firmó el consentimiento informado. Además, se empleó una ficha de recolección de datos con un pseudónimo para el investigado (una letra seguida de un número: "S"- personal de salud, "R"- potencial receptor y "F"- familiar de potencial donante). Para el registro de información se usó una grabadora y se partió de la pregunta "¿qué entiende usted por donación de órganos?”, conforme las respuestas, se introdujeron interrogantes sobre la lista de temas. La entrevista finalizó por saturación teórica de cada estamento, es decir, cuando no se encontraron datos adicionales o estos se repetían.

\section{ANÁLISIS DE DATOS}

El análisis de datos se hizo con ayuda del software QDA (análisis cualitativo de datos) ATLASti versión 7.0. El proceso para cada estamento fue: transcripción exacta de la entrevista; reducción del texto, tomando en cuenta el marco teórico y guía elaborada; foco del análisis o fase de descubrimiento: se examinaron los datos a fin de obtener "temas" de estudio; categorización: clasificación de datos según su contenido en común y vinculación hacia un tema; fase de codificación: al leer las entrevistas los fragmentos de interés se asociaron a la categoría de un tema mediante un código (número). Así, mientras se realizaba el análisis, se pudo redefinir la codificación y categorías ajustándolos a los datos; reunión de los fragmentos de cada categoría; integración local: es decir, integración total de las categorías dentro de cada tema correspondiente. A su vez, permitió redefinir nuevas categorías gracias a la riqueza de información brindada y se evidenció saturación teórica; integración inclusiva: organización de cada tema que representan los mitos del estudio; verificación de datos: se realizó triangulación de los datos obtenidos en los tres estamentos. La triangulación ayuda a dilucidar las diferentes partes complementarias de la totalidad del fenómeno y verifica la repetitividad de una observación. Se redefinieron las categorías por última vez. Se contactó a cada sujeto y se explicaron los mitos captados; presentación de los datos: según temas identificados. Los mitos se presentan como corta cita textual dentro de cada tema. Las citas más representativas se incluyen en resultados.

\section{CONSIDERACIONES ÉTICAS}

El proyecto fue aprobado por el Comité de Ética de Investigación de la Facultad de Medicina de la Universidad Católica Santo Toribio de Mogrovejo y por el Comité de Ética del Hospital Nacional Almanzor Aguinaga Asenjo. Los investigados participaron voluntariamente firmando el consentimiento informado, se protegió su anonimato y se informó la posibilidad de publicar esta investigación en una revista científica. 
Tabla 1. Características sociodemográficas de los entrevistados

\begin{tabular}{lrr}
\hline Características & $\mathbf{n}$ & \multicolumn{1}{c}{$\%$} \\
\hline Estamentos & & \\
\hline Potenciales receptores & 8 & 33,3 \\
\hline Familiares de potenciales donantes & 7 & 29,2 \\
\hline Personal de salud & 9 & 37,5 \\
\hline Edad & & \\
\hline $20-35$ años & 5 & 20,8 \\
\hline 35-50 años & 6 & 25 \\
\hline 50-65 años & 13 & 54,2 \\
\hline Sexo & & \\
\hline Masculino & 8 & 33,3 \\
\hline Femenino & 16 & 66,7 \\
\hline Grado de instrucción & & \\
\hline Sin nivel & 0 & 0 \\
\hline Primaria & 5 & 20,8 \\
\hline Secundaria & 6 & 25 \\
\hline Superior & 13 & 54,2 \\
\hline Religión & & \\
\hline Católica & 21 & 87,5 \\
\hline No católica & 3 & 12,5 \\
\hline Estado civil & & \\
\hline Soltero & 3 & 12,5 \\
\hline Casado & 17 & 70,8 \\
\hline Viudo & 4 & 16,7 \\
\hline Divorciado & 0 & 0 \\
\hline & & \\
\hline
\end{tabular}

TEMA 1: OPINIÓN SOBRE LA DONACIÓN DE ÓRGANOS

\section{Donar es positivo}

"Es un acto de vida hacia otra persona" (S1).

"Es algo positivo, deberíamos de catalogar al donante como un héroe" (F6).

"Es uno de los desprendimientos más grandes que pueda hacer el ser humano en favor de su prójimo" (R4).

\section{Donar es negativo}

"No estoy de acuerdo con que la gente done órganos, para mí es igualito a vender" (R7).

\section{TEMA 2: INSCRIPCIÓN COMO DONANTES (DNI)}

"Dice que no, mira, porque son unos infelices, osea nunca me preguntaron. Todos mis DNI dicen que no. A la última le dije por si acaso "sí" y copiaron igualito nomás, es que muchas veces no preguntan los que trabajan en la RENIEC" (S6).

"Yo sí quisiera donar, pero mira mi DNI dice "no". No me preguntaron ni nada" (F2).

Tabla 2. Temas y mitos sobre la donación de órganos según cada estamento entrevistado

\begin{tabular}{|c|c|c|c|c|c|}
\hline Temas y mitos & $\begin{array}{c}\text { Personal } \\
\text { de Salud } \\
\quad(n=9)\end{array}$ & $\begin{array}{l}\text { Potenciales } \\
\text { receptores } \\
\quad(n=8)\end{array}$ & $\begin{array}{l}\text { Familiares de } \\
\text { potenciales } \\
\text { donantes } \\
(n=7)\end{array}$ & $\begin{array}{l}\text { Total } \\
(\mathbf{N}=24)\end{array}$ & $\begin{array}{c}\text { Total } \\
(\%)\end{array}$ \\
\hline \multicolumn{6}{|l|}{ Tema 1. Opinión sobre la donación de órganos } \\
\hline Donar es positivo & 9 & 7 & 7 & 23 & 95,8 \\
\hline Donar es negativo & 0 & 1 & 0 & 1 & 4,2 \\
\hline \multicolumn{6}{|l|}{ Tema 2. Inscripción como donantes (DNI) } \\
\hline Sí & 5 & 2 & 4 & 11 & 45,8 \\
\hline No & 4 & 6 & 3 & 13 & 54,2 \\
\hline \multicolumn{6}{|l|}{ Tema 3. Contraindicaciones para donar } \\
\hline "La edad limita donar" & 3 & 5 & 3 & 11 & 45,8 \\
\hline "Hay enfermedades que no permiten donar" & 6 & 2 & 1 & 9 & 37,5 \\
\hline \multicolumn{6}{|l|}{ Tema 4. Trascendencia de la donación } \\
\hline $\begin{array}{l}\text { "El receptor adopta los gustos, sentimientos o personalidad } \\
\text { del donador" }\end{array}$ & 4 & 5 & 6 & 15 & 62,5 \\
\hline "El ser amado vive en otro" & 3 & 2 & 6 & 11 & 45,8 \\
\hline \multicolumn{6}{|l|}{ Tema 5. Concepción de la muerte cerebral } \\
\hline "La muerte cerebral es inmovilidad" & 6 & 4 & 2 & 12 & 50 \\
\hline "La muerte cerebral es reversible" & 6 & 3 & 3 & 12 & 50 \\
\hline \multicolumn{6}{|l|}{ Tema 6. Rol de la religión } \\
\hline "Mi religión no está de acuerdo con la donación" & 2 & 4 & 3 & 9 & 37,5 \\
\hline $\begin{array}{l}\text { "La donación de órganos afecta la integridad física y } \\
\text { resurrección" }\end{array}$ & 7 & 6 & 2 & 15 & 62,5 \\
\hline \multicolumn{6}{|l|}{ Tema 7. Proceso de la donación de órganos } \\
\hline "Hay preferencias en la lista de espera de donantes" & 2 & 6 & 2 & 11 & 45,8 \\
\hline "Existe tráfico de órganos" & 8 & 7 & 5 & 20 & 83,4 \\
\hline "Si el hospital sabe que soy donante me trataría distinto" & 1 & 5 & 3 & 9 & 37,5 \\
\hline
\end{tabular}


TEMA 3: CONTRAINDICACIONES PARA DONAR ÓRGANOS

\section{La edad limita donar}

"Hasta cierta edad creo que son hasta los 50 años o 45 años que se puede donar" (S5).

"La edad tiene mucho que ver. Si eres joven puedes donar, pero los mayores de 60 ya no" (F3).

"Si eres cuarentón no puedes donar, los órganos están viejos" (R2).

\section{Hay enfermedades que no permiten donar}

"Tengo entendido que no pueden donar las personas con problemas cardiacos de presión, de azúcar, hígado, también con cáncer y con infecciones de virus" (F2).

"Sobre todo, en el tema de las infecciosas virales ¿no? tipo hepatitis, HIV, enfermedades transmisibles, son factores que van en contra de una donación" (S8).

"Que no sea un paciente hipertenso, si lo es no puede donar" (R4).

\section{TEMA 4: TRASCENDENCIA DE LA DONACIÓN}

\section{EI receptor adopta los gustos, sentimientos 0 personalidad del donador}

"Si él en su juventud ha tenido agresividad y recibe un órgano que le han donado de una persona que ama a Dios, creo que cambiaría, sería más bueno" (R5).

"Cuando murió ella su enamoradito quería que done su corazón. Él me preguntó si sus sentimientos por él los tendría la otra persona" (F6).

"Yo sí he conocido a una paciente que después que le donaron riñón decía que le gustaba cosas que antes no. $Y$ averiguando así, eran cosas que a su donador le gustaban" (S3).

"He tenido un paciente medio tronadito. Él tenía como cuarenta años y le habían puesto un riñón de uno de veinte y me decía 'ipues doctor; me siento jovencito! míreme, me siento como un fulano de treinta, lleno de vigor...'. No ha de ser que a los hombres que les trasplantan un riñón de mujer se tengan que sentar para orinar" (S6).

\section{El ser amado vive en otro}

"Hay una parte de mí que va a estar en esa persona y estoy viviendo todavía, de alguna forma. Tan solo saber que estoy viviendo ahí, es presenciarme en esa persona" (S4).
"Ponte si fuera el órgano de una hermana mía la vería así como una hermana mía, sentiría que mi hermana aún está viva" (R4).

"Me siento contenta porque mi hermano tiene sus órganos en otra persona, y se encuentra vivo para mí; para mí no está muerto, se encuentra vivo en otra persona que tiene su órgano" (F1).

"Los ojos de mi hijo siguen viendo el mundo, ahí un pedacito de mi hijo está vivo dentro de una persona" (F4).

\section{TEMA 5: CONCEPCIÓN DE LA MUERTE CEREBRAL}

\section{La muerte cerebral es inmovilidad}

"Llega un momento en que se rompe todo y ya se muere, ahí se queda tu cuerpo inmóvil" (R7).

"Había un aparato que marcaba las ondas, y cuando dejó de funcionar y se convirtió en una línea continua eso era muerte cerebral; que el cuerpo estaba quieto y seguía funcionando por efecto de la máquina" (F4).

"Muerte cerebral es el paciente que está desconectado del mundo externo... osea, su sistema nervioso ha perdido la capacidad de mirar, escuchar, pensar, sentir" (S9).

\section{La muerte cerebral es reversible}

"Yo tenía la esperanza que salga de la muerte cerebral porque había visto casos de que cuando están así en coma después despiertan" (F6).

"Era una joven de veinticuatro años, había terminado la carrera de derecho, hizo un sangrado masivo cerebral; subió a $\mathrm{UCl}$, le insistían que le hagan las pruebas para donar; se resistía el familiar. Al día siguiente despertó la joven, salió de la muerte cerebral" (S4).

"Para los pacientes es voy a sacar la parte de mi ser vivo, es recién matarlos" (S1).

"Una vez vi un chico que había sufrido un accidente y lo declararon en muerte cerebral pero luego normal vivió el chico" (R3).

A propósito de ello se reporta como hallazgo una vivencia médica:

"Les cuento algo que me sucedió a mí: una señora que había tomado cualquier cantidad de alcohol y la golpea una mototaxi, la llevan al hospital, yo llego y la examino... muerte encefálica, pregunto por la donación al papá y acepta, la traigo acá y en el camino comienza a estirarse "ouh"' (S6). 
TEMA 6: ROL DE LA RELIGIÓN EN LA DONACIÓN DE ÓRGANOS

\section{Mi religión no está de acuerdo con la donación}

"La sangre es sagrada, es la vida del ser humano y le pertenece a Dios y si uno hace un trasplante es como si estuvieras comiendo la sangre, estás desobedeciendo a Dios" (R1) (testigo de Jehová).

"Algunos se mantienen neutrales, otros dicen que no, que Dios se va a molestar porque él no ha autorizado la donación de órganos" (R6) (evangélico).

"En la Biblia no está eso, que donemos nuestros órganos. Para mí como cristiana, sabemos que Jesús murió y no donó órganos a nadie entonces no estaría bien la donación de órganos. Los papas tampoco están de acuerdo" (R7) (católico).

\section{La donación de órganos afecta la integridad física y resurrección}

"Dicen los evangélicos que si donas, cuando haya la resurrección o cuando venga Dios, nuestras almas no van a estar completas y no se van a salvar" (F3).

"La donación afecta la integridad física e incluso el deseo de ir completos a la sepultura y no ser cortados para preservar la conexión con el alma" (R6).

"Muchas veces no han aceptado la donación porque quieren que vaya completo el paciente al cementerio. No quieren que después su alma esté vagando" (S3).

\section{TEMA 7: PROCESO DE LA DONACIÓN DE ÓRGANOS}

\section{Hay preferencias en la lista de espera de donantes}

"Tengo una amiguita que está en la lista de espera, ella me dice que se maneja internamente, dice que ha escuchado que ahí corre dinero" (S5).

"Debe haber conocidos o hay dinero para que avance más rápido. Por decir, yo la conozco y usted trabaja en un hospital, entonces me pasa la voz que hay un riñón y peor si hay dinero: doctor sabe yo sé que hay un donante, le doy tanto, póngamelo a mí" (R4).

"Hay preferencias en la lista de espera. Los primeros son los beneficiados... si la persona tiene pocos recursos económicos será difícil que le donen" (F7).

\section{Existe tráfico de órganos}

"Ha habido casos concretos de que se hicieron incluso en algunas clínicas particulares, no sé cuales..., pero justamente el tema de las mafias que trafican con órganos se da. Alguna vez lo vi en la tv" (S8).
"Aparecen cadáveres sin ojos, sin riñón, sin corazón, los habrán matado para robarles sus órganos. Pero tienen que haber médicos y enfermeras involucrados. Ahí en Lambayeque había una niñita que la encontraron sin ojos me contaron" (R2).

"Los canales peruanos lo único que propagan es que se compran riñones, se compran hígados, a tremendas sumas. Así trafican ahora" (F4).

\section{Si el hospital sabe que soy donante me trataría distinto}

"Si tengo un accidente y llego moribunda me van a atender rápido porque van a querer mis órganos $\mathrm{Si}$ el doctor dice este órgano lo necesito, voy a sacarlo y voy a darlo" (R4).

"Me decían que si en mi DNI aceptaba, más rápido me iban a matar, o no me iban a atender en los hospitales" (F2).

"Me tratarían distinto porque estoy disponible para donar a cualquier persona. Entonces si tengo un accidente y si tengo mis órganos buenos, rápido me los sacan" (S1).

\section{DISCUSIÓN}

Los mitos explorados sobre la donación de órganos fueron: la edad como limitación; las enfermedades que contraindican donar; la adopción de gustos, sentimientos o personalidad del donador; el donador viviendo en otro ser; la muerte cerebral como inmovilidad y estado reversible; las religiones en contra de la donación de órganos y cómo esta afecta la integridad física y la resurrección; preferencias en la lista de espera de donantes; el tráfico de órganos y, finalmente, la actitud hospitalaria ante el donante.

Existe discordancia entre la expresión verbal hacia la donación de órganos y la escrita en el documento nacional de identidad, doce entrevistados que manifiestan su deseo de ser donantes podrían no llegar a serlo si fallecieran. Este problema se atribuye a una falta de adherencia al procedimiento por parte del funcionario del Registro Nacional de Identificación y Estado Civil (RENIEC) ${ }^{(0,19)}$.

La edad o enfermedades como contraindicaciones para la donación de órganos coinciden con el estudio de Leonard en Argentina. El 33 y $29 \%$ de los encuestados asociaron enfermedades y una edad límite, respectivamente, como obstáculos para donar. Las únicas contraindicaciones aceptadas fueron infecciones por HTLV, tuberculosis activa, VIH en estadio SIDA, encefalitis por rabia o priones, melanoma maligno, neoplasias con metástasis o shock séptico ${ }^{(20,21)}$.

La adopción de caracteres de los donantes en sus receptores y la idea de vivir en otro ser resalta en esta 
investigación, sobre todo en los familiares de potenciales donantes. Un estudio sobre el trasplante de córnea halló que el rol de los ojos en la memoria y comunicación era un factor de rechazo al mismo. Ello evidencia una creencia en la conexión del tejido y los recuerdos aun tras la muerte. Por otro lado, parece ser que los familiares de donantes buscan un resultado positivo del fallecimiento del ser amado y crean un recuerdo vivo de ellos. Estos hallazgos se relacionan con una mayor apertura mental y menor rigidez de pensamiento en personas que aceptan la donación de órganos ${ }^{(22-24)}$.

La creencia de muerte cerebral como inmovilidad del cuerpo y estado reversible, refleja un bajo nivel de conocimiento, sobre todo del personal de salud $(1,21)$. Los encargados del diagnóstico son mayoritariamente intensivistas. El desconocimiento de los requisitos para su identificación (coma arreactivo, ausencia de reflejos del tronco y respiración espontánea, prueba de atropina) por parte de los médicos, genera conjeturas erróneas en la población. Así, pacientes con "muerte cerebral" pueden retornar a su función neurológica si el proceso diagnóstico fue erróneo ${ }^{(1,7,25)}$.

Reafirmando las opiniones negativas registradas por el Servicio de Procuración de Órganos y Tejidos, los sujetos mencionan que sus religiones se oponen a la donación de órganos ${ }^{(8)}$. Según diversos estudios, las creencias religiosas son un obstáculo importante para donar. Incluso cuando ninguna religión se opone a la donación y, por el contrario, la consideran un acto libre y de generosidad hacia el prójimo. Así, el temor a ser mutilado o no participar de la resurrección compromete la decisión de ser donante ${ }^{(7,9,26,27,28)}$.

El proceso de la donación de órganos no es confiable para los investigados. Creen en la existencia de preferencias en la lista de espera, tal como el estudio de Leonard. Afirman que los ricos se benefician primero ${ }^{(21)}$. Además, otros estudios manifiestan temor ante la posibilidad de la extracción de órganos sanos ${ }^{(9,28)}$. El tráfico de órganos, mito más frecuente del presente estudio, es reconocido como: compraventa de órganos (principalmente riñones) u obtención criminal de los mismos. La fuente más común de órganos son India, Pakistán, Egipto, Filipinas, China y Latinoamérica (Colombia) ${ }^{(29)}$. Sobre la obtención criminal, los medios de comunicación especulan sobre asesinatos con fines de extraer órganos. Sin embargo, por la gran complejidad del proceso prequirúrgico y de trasplante estas prácticas temibles serían improductivas aún para las grandes mafias ${ }^{(2,29,30)}$. En el 2013, médicos alemanes manipularon datos de pacientes para lograr una prioridad del órgano para sus pacientes, alimentando así la desconfianza popular ${ }^{(16)}$.

Se reportan como limitaciones, en primer lugar el tamaño de la muestra. Es necesario establecer que los resultados del estudio, aunque sean significativos, no pueden ser considerados como definitivos en otro contexto ya que se trata de una investigación cualitativa con valor en tiempo y espacio dado. En segundo lugar, todos los entrevistados, como los familiares de potenciales donantes, fueron personas que aceptaron la donación ya que no se pudo localizar a quienes se negaron por motivos de mudanza, cambio de número telefónico o similar. Solo tres del total de contactados se negaron a la entrevista sin expresar motivo.

En conclusión, los mitos explorados en el presente estudio muestran perspectivas religiosas, socioculturales, psicológicas y éticas. La aparente falta de conocimiento del real diagnóstico de muerte cerebral es el punto de partida que marca el proceso de donación. La existencia de un coordinador hospitalario cuya misión sea difundir y promover la donación de órganos combatiendo los mitos encontrados, es fundamental. Asimismo, el rol de los guías espirituales alentando en esta expresión de amor al prójimo. Finalmente, es de urgencia que los medios de comunicación propaguen información adecuada sobre el tema y se renueven políticas contra la compraventa de órganos.

Contribuciones de autoría: KGR, JBL y FLJ participaron en la concepción del artículo. KGR y JBL fueron instruidos en el tema por el Servicio de Procuración de Órganos y Tejidos de la región macronorte del Perú. KGR realizó las entrevistas y JBL su redacción textual. Los tres autores participaron del análisis de datos, interpretación y redacción del artículo final.

Fuente de financiamiento: autofinanciado.

Conflictos de interés: los autores niegan algún conflicto de interés.

\section{REFERENCIAS BIBLIOGRÁFICAS}

1. Ley general de donación y trasplantes de órganos y/o tejidos humanos de Perú. Ley 28189. (24 de febrero del 20144).

2. Organización Nacional de Trasplantes de España. International Figures On Donation And Transplantation.
Newsletter Transplant. 2014;19(1):150.

3. Matesanz R, Domínguez-Gil B, Coll E, de la Rosa G, Marazuela R. Spanish experience as a leading country: what kind of measures were taken?. Transpl Int. 2011;24(4):333-43. doi: 10.1111/j.1432-2277.2010.01204.x.

4. Prieto M, Clemente G, Casafont F, Cuende N, Cuervas-Mons V, Figueras J, et al. Documento de consenso de indicaciones de trasplante hepático. Gastroenterol Hepatol. 2003;26(6):355-75. 
5. Barriga C, Baeza R, Pereira J, Besa P, Caldumbide I, Medel M. Trasplante de médula ósea en pacientes pediátricos. Rev Chil Pediatr. 1999;70(3):194-200. http://dx.doi.org/10.4067/S037041061999000300004

6. Alonso-Pulpón L, Almenar L, Crespo MG, Silva L, Segovia J, Manito N, et al. Guías de actuación clínica de la Sociedad Española de Cardiología. Trasplante cardiaco y de corazón-pulmones. Rev Esp Cardiol. 1999;52(10): 821-39.

7. Guerra R. Donación de órganos: comprensión y significado. [Tesis Bachiller]. Chile: Universidad de Chile; 2005.

8. Servicio de Procuración de Órganos y Tejidos de región macronorte del Perú. Actividad donadora y de trasplantes en la región macronorte [CD-ROM]. Perú; 2013.

9. Nazario Z. Actitudes y creencias de los adultos jóvenes frente a la donación de órganos. [Tesis Bachiller]. Perú: Universidad Santo Toribio de Mogrovejo; 2011.

10. Ríos A, López-Navas A, Ayala-García MA, Sebastián MJ, Abdo-Cuza A, Alán J, et al.Spanish-Latin American multicenter study of attitudes toward organ donation among personnel from hospital healthcare centers. Cir Esp. 2014; 92(6):393-403. doi: 10.1016/j. ciresp.2013.12.017.

11. Neciosup V. informe de Investigación 83/2014-2015. Donación y trasplante de órganos en el Perú [internet]. Perú: Congreso de la República-área de servicios de investigación; 2014 [citado el 09 de marzo de 2016]. Disponible en: http://www.academia.edu/9156993/ D O N A C I \% C $3 \% 93 \mathrm{~N}_{-} \mathrm{Y}_{-}$ T R A S P L A N $\mathrm{T}$ E _ DE_\%C3\%93RGANOS_EN_EL_ PER\%C3\%9A

12. Loza C. La enfermedad renal crónica en el Perú, epidemiología e impacto de la salud pública. Bol Epidemiol (Lima). 2014;23(3):36-8.
13. Palacios J. Procuramiento de órganos: "El Modelo Chileno". Rev Chilena de Cirugía. 2002;54(6):573-88.

14. López JS, Valentín MO, Scandroglio B, Coll E, Martín MJ, Sagredo E, et al. Factors related to attitudes toward organ donation after death in the immigrant population in Spain. Clin Transplant. 2012;26(3):E200-12. doi: 10.1111/j.1399-0012.2011.01586.x.

15. Da Silva IR, Frontera JA. Worldwide Barriers to Organ Donation. JAMA Neurol. 2015;72(1):112-8. doi: 10.1001/jamaneurol.2014.3083.

16. Trey T, Caplan AL, Lavee J. Transplant ethics under scrutiny - responsibilities of all medical professionals. Croat Med J. 2013;54(1):71-4.

17. Taipe N. Los mitos. Consensos, aproximaciones y distanciamientos teóricos. Gazeta de Antropología. 2004;20(16):1-21.

18. Ley que promueve la obtención, la donación y el trasplante de órganos o tejidos humanos. Ley $\mathrm{N}^{\circ} 29471$ (21 de noviembre del 2013).

19. Organización Panamericana de la Salud. Legislación sobre donación y trasplante de órganos, tejidos y células: compilación y análisis comparado. Washiton D.C.: OPS; 2013.

20. Directiva 003: Norma técnica para los procesos de trasplantes. Gerencia General-Essalud, 270 (15 de febrero del 2011).

21. Leonard MV. Mitos y creencias sobre la donación de órganos [internet]. Argentina: Universidad Nacional de Tucumán; 2004 [citado el 24 mayo de 2014]. Disponible en: http://www. herrera.unt.edu.ar/eiii/concepcion/ pasins/m.veronica\%20leonard.pdf

22. Lawlor M, Kerridge I. Understanding selective refusal of eye donation. Identity, beauty, and interpersonal relationships. J Bioeth Inq. 2014;11(1):57-64. doi: 10.1007/ s11673-013-9497-9.

23. Manuel A, Solberg S, MacDonald S. Organ donation experiences of family members. Nephrol Nurs J. 2010;37(3):229-36.
24. Blanca MJ, Rando B, Frutos MA, López-Montiel G. Perfil psicológico de potenciales donantes y no donantes de órganos. Psicothema. 2007;19(3):440-5.

25. Matesanz R. El diagnóstico de la muerte encefálica en Latinoamérica. Med Intensiva. 2009;33(9):413-4. doi: 10.1016/j.medin.2009.07.006.

26. Tarthan M, Dalar L, Yildirimoglu H, Sayar A, Altin S. The view of religious officials on organ donation and transplantation in the Zeytinburnu district of Istanbul. J Relig Health. 2015;54(6):1975-85.

27. Messina E. Beyond the Officially sacred, donor and believer: religion and organ transplantation. Transplant Proc. 2015;47(7):2092-6. doi: 10.1016/j.transproceed.2015.06.031.

28. Scandroglio B, Domínguez-Gil B, López JS, Valentín MO, Martín MJ, Coll E, et al. Analysis of the attitudes and motivations of the Spanish population towards organ donation after death. Transpl Int. 2011;24(2):158-66. doi: 10.1111/j.1432-2277.2010.01174.x.

29. Danovitch GM, Chapman J, Capron AM, Levin A, Abbud-Filho $\mathrm{M}$, Al Mousawi $\mathrm{M}$, et al. Organ traffincking and transplant tourism: the role of global profesional ethical standards-the 2008 Declaration of Istanbul. Trasplantation. 2013;95(11):1306-12. doi: 10.1097/ TP.0b013e318295ee7d.

30. Matesanz R. Tráfico de órganos: hechos, ficciones y rumores. Rev Nefrología. 1994;14(6):633-45.

Correspondencia: Katherine Giuliana Gómez Rázuri

Dirección: Residencial Augusto B. Leguía edificio 2 departamento 403. Chiclayo, Perú.

Teléfono: (511) 959851398

Correo electrónico:k-rgb12@hotmail.com 
Anexo 1. Guía básica de preguntas

¿Qué entiende usted por donación de órganos?

Donación de paciente vivo o cadavérico

Requisitos para donar

¿Qué es muerte cerebral/encefálica?

¿Qué opina acerca de la donación de órganos?

¿Es gratuita?

¿Qué significa la muerte para usted?

¿Qué opina su religión?

¿Qué dice su DNI? ¿Qué es lista de espera y de qué depende?

¿Qué pasaría si tuviera que tomar la decisión de donar los órganos de algún familiar? ¿Qué significaría para usted el receptor?

¿Qué opina su familia y/o amigos acerca de la donación de órganos? ¿Escuchó otras opiniones de terceras personas?

¿Qué siente al pensar que usted alguna vez pudiera ser donante? ¿Por qué? ¿Qué órganos le gustaría donar y por qué?

¿Qué cree que sucedió con los órganos de su familiar si usted aceptó la donación?

F Hubo un seguimiento después o le habría gustado

¿Cómo fue el trato del hospital, le ayudó en su decisión?

¿Existió duda si el familiar realmente había fallecido?

$\mathbf{R} \quad$ Si usted recibiera la donación de un órgano, ¿qué cree que pasaría en su vida?

S Si uno de sus pacientes se encuentra apto para donar órganos, ¿qué le diría a la familia? Recuerda alguna anécdota respecto al tema en su trabajo

Nota. Esta guía no es una entrevista estructurada, el investigador decidió cómo iniciar la entrevista y de acuerdo a cada respuesta reformuló las preguntas necesarias a fin de explorar el objeto de estudio. La presente lista es solo una base con la cual puntos clave no fueron olvidados y, asimismo, se añadieron preguntas conforme cada sujeto fue entrevistado.

\section{Consulte la versión electrónica de la} Revista Peruana de Medicina Experimental y Salud Pública en

\section{www.pubmed.gov}

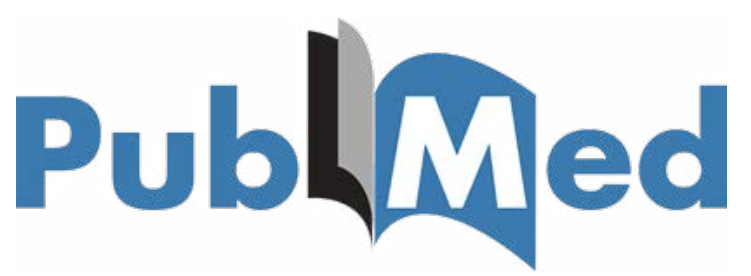

